\title{
Estimating the asbestos-related lung cancer burden from mesothelioma mortality
}

\author{
V McCormack', J Peto ${ }^{2}$, G Byrnes ${ }^{3}$, K Straif ${ }^{4}$ and P Boffetta ${ }^{*, 5,6}$ \\ 'Section of Environment and Radiation, International Agency for Research on Cancer, 150 cours Albert Thomas, Lyon 69008, France; ${ }^{2}$ Faculty of \\ Epidemiology and Population Health, Department of Epidemiology, London School of Hygiene \& Tropical Medicine, Keppel Street, London WCIE 7HT, \\ UK; ${ }^{3}$ Biostatistics Group, Section of Genetics, International Agency for Research on Cancer, 150 cours Albert Thomas, Lyon 69008, France; ${ }^{4}$ Section of \\ IARC Monographs, International Agency for Research on Cancer, 150 cours Albert Thomas, Lyon 69008, France; ${ }^{5}$ Institute for Translational Epidemiology \\ and Tisch Cancer Institute, Mount Sinai School of Medicine, One Gustave L. Levy Place, New York, NY 10029-6574, USA; ${ }^{6}$ International Prevention \\ Research Institute, Lyon, France
}

BACKGROUND: Quantifying the asbestos-related lung cancer burden is difficult in the presence of this disease's multiple causes. We explore two methods to estimate this burden using mesothelioma deaths as a proxy for asbestos exposure.

METHODS: From the follow-up of 55 asbestos cohorts, we estimated ratios of (i) absolute number of asbestos-related lung cancers to mesothelioma deaths; (ii) excess lung cancer relative risk (\%) to mesothelioma mortality per 1000 non-asbestos-related deaths. RESULTS: Ratios varied by asbestos type; there were a mean 0.7 ( $95 \%$ confidence interval $0.5,1.0)$ asbestos-related lung cancers per mesothelioma death in crocidolite cohorts ( $n=6$ estimates), $6.1(3.6,10.5)$ in chrysotile $(n=16), 4.0(2.8,5.9)$ in amosite $(n=4)$ and $1.9(1.4,2.6)$ in mixed asbestos fibre cohorts $(n=31)$. In a population with 2 mesothelioma deaths per 1000 deaths at ages $40-84$ years (e.g., US men), the estimated lung cancer population attributable fraction due to mixed asbestos was estimated to be $4.0 \%$. CONCLUSION: All types of asbestos fibres kill at least twice as many people through lung cancer than through mesothelioma, except for crocidolite. For chrysotile, widely consumed today, asbestos-related lung cancers cannot be robustly estimated from few mesothelioma deaths and the latter cannot be used to infer no excess risk of lung or other cancers.

British Journal of Cancer (2012) 1 06, 575-584. doi:I0.1038/bjc.201 I.563 www.bjcancer.com

Published online 10 January 2012

(C) 2012 Cancer Research UK

Keywords: asbestos; lung cancer; mesothelioma; chrysotile

Asbestos is an established human carcinogen, the major effects being on cancers of the lung and mesothelioma of the pleura and peritoneum (IARC, 1987). Inhalation of asbestos fibres predominantly occurs during occupational exposure including in mines, construction, shipyards, railway and textile industries. Restrictions or bans on the use of certain asbestos fibres were introduced in the United States and Europe from the 1980s onwards, but latency periods of several decades mean that the mesothelioma epidemic is yet to peak. In 2000, an estimated 43000 malignant mesotheliomas worldwide were due to occupational exposures (Driscoll et al, 2005), the largest absolute burdens being in the United States, Australia, Japan, New Zealand and Western Europe (Peto et al, 1999). Global asbestos (chrysotile) consumption was 2.3 million tonnes in 2003, predominantly in the lower income countries (Virta, 2006). The asbestos-related lung cancer (ARLC) burden is more difficult to quantify as most lung cancers are not attributable to asbestos, unlike for mesothelioma (Bianchi and Bianchi, 2007). ARLCs occur on top of varying lung cancer incidence rates and they are not clinically distinguishable from those not caused by asbestos. Furthermore, reliable population-based data on asbestos exposure (by fibre type, length, age at exposure, intensity) and

*Correspondence: Dr P Boffetta; E-mail: paolo.boffetta@mssm.edu Received 13 September 201 I; revised 21 November 201 I; accepted 23 November 20I I; published online 10 January 2012 associated relative risks are not known precisely, preventing the calculation of population attributable fractions (PAFs).

We present two methods to estimate the relationship between ARLC deaths and mesothelioma deaths, using the latter as a proxy for asbestos exposure. The first is the ratio of absolute excess lung cancer deaths to mesothelioma deaths. However with a synergistic interaction between asbestos and smoking on lung cancer, the ARLC burden will be particularly large in settings where smoking rates are high, thus a more appropriate ratio may be a relative effect on lung cancer to the absolute effect on mesothelioma. Using published cohorts of asbestos-exposed workers, we summarise these two ratios by asbestos type to gauge the magnitude of the population-level ARLC burden in different countries.

\section{MATERIALS AND METHODS}

\section{Ratio estimates}

We estimated the ratio of asbestos-related lung cancers to mesothelioma deaths from asbestos cohorts. Two ratios were calculated for each cohort. Method 1: the absolute ratio $\left(R_{1}\right)$ of the absolute number of ARLC deaths to mesothelioma deaths is estimated by $R_{1}=\left(O_{\mathrm{LC}}-E_{\mathrm{LC}}\right) / O_{\mathrm{M}}$, where $O$ and $E$ refer to the observed deaths and expected deaths in the absence of asbestos, with subscripts LC and $M$ referring to lung cancer and 
mesothelioma, respectively. $E_{\mathrm{LC}}$ was estimated as $O_{\mathrm{LC}} / \mathrm{SMR}$, the SMR being the standardised mortality ratio for lung cancer, which was usually provided. Method 2: the proportional ratio $\left(R_{2}\right)$ is the ratio of the excess lung cancer percentage for every mesothelioma death in 1000 non-asbestos-related deaths, $R_{2}=\left[100 \times\left(O_{\mathrm{LC}}-E_{\mathrm{LC}}\right) / E_{\mathrm{LC}}\right] /\left[1000 \times O_{\mathrm{M}} / E_{\mathrm{all}}\right]$, where $E_{\text {all }}$ refers to expected deaths from all causes in the absence of asbestos, estimated as observed deaths minus (excess lung cancers + mesotheliomas $) \quad\left(=O_{\mathrm{all}}-\left(O_{\mathrm{LC}}-E_{\mathrm{LC}}\right)-O_{\mathrm{M}}\right)$. We assumed no expected mesothelioma deaths in the absence of asbestos. Note $R_{2}=R_{1} \times E_{\text {all }} /\left(10 \times E_{\mathrm{LC}}\right)$

Given a particular type of asbestos exposure, ratio $R_{1}$ will only be constant in populations with similar background smoking and lung cancer incidence rates if there is a proportional increase in lung cancer risk associated with exposure (i.e., constant relative risk). As lung cancer incidence rates vary between countries and over time, the ratio of the relative effect on lung cancer to the absolute effect on the mesothelioma mortality rate may be more constant. We attempt to estimate this in ratio $R_{2}$. Its numerator is the excess relative risk percentage. The denominator would ideally be an age-standardised mesothelioma mortality rate, but as this rate was rarely reported in included cohorts, the number of mesothelioma deaths per 1000 non-asbestos-related deaths $\left(E_{\text {all }}\right)$ was used as a correlate. Thus $R_{2}$ is the excess lung cancer relative risk (expressed as a percentage) for every mesothelioma death in 1000 non-asbestos-related deaths.

\section{Included studies and data extraction}

Asbestos cohorts were identified via a PubMed search, last updated on 1 September 2011, of all articles containing the MeSH terms 'Neoplasms', 'Cohort Studies' and 'asbestos', yielding 425 results. Reference lists of retrieved articles and previous relevant reviews were also checked for omissions (Hodgson and Darnton, 2000; Boffetta, 2007). For the British Asbestos Survey, data were extracted from an online report (Harding, 2010). Eligible studies included were those with (i) at least 100 subjects, (ii) certain asbestos exposure (not just probable such as in environmental settings) and (iii) observed and expected (based on country-level rates or an unexposed cohort) mesothelioma and lung cancer mortality or incidence for the same follow-up period. Cohorts consisting entirely of asbestosis or pleural disease patients were not included. For cohorts with multiple publications, the most informative recent one was included. From each included publication we extracted information on cohort characteristics, asbestos fibre type (crocidolite/chrysotile and crocidolite/pure or predominantly chrysotile/amphiboles including amosite/mixed or unspecified), industry, cause of death ascertainment, whether lung cancer SMRs were adjusted for smoking (or whether smoking prevalence was comparable with that of the reference population), total number of deaths and observed and expected deaths from lung cancer and mesothelioma. Incidence data were used if mortality data were not available (not contributing to $R_{2}$ ). Expected deaths were usually estimated by authors from population-level age-sex-period-specific mortality rates. For the Great Britain Asbestos Survey, excess lung cancers were calculated from proportional mortality ratios rather than SMRs in order to minimise confounding by smoking (Harding, 2010). Where appropriate, mortality was based on best evidence rather than death certificate only. In some instances only pleural mesotheliomas were recorded (indicated in tables).

As our aim was to summarise the overall association between the ARLC and mesothelioma mortality to reflect estimates of the average association effect, we did not carry out a meta-regression of all possible factors that might affect an individual ratio (other than asbestos type and confounding by smoking). This average association is useful because a mesothelioma burden at the population level arises from differing exposure conditions, as reflected in those from the various cohorts included.

\section{Statistical methods}

Extracted data were used to calculate $R_{1}$ and $R_{2}$ as defined. Estimates of $R_{1}$ were plotted by asbestos type, with the variance of $\log \left(R_{1}\right)$ estimated as $\left(1 / E_{\mathrm{LC}}+1 / E_{\mathrm{M}}\right)$ and for $R_{2}$ as $\left(1 / E_{\mathrm{LC}}+1 / O_{\mathrm{M}}+\right.$ $\left.1 / O_{\text {all }}\right)$. Summary values of $R_{1}$ and $R_{2}$ and of SMRs for lung cancers were obtained from a random-effects meta-analysis implemented in STATA version 11. Meta-regression models were used to examine whether the ratio estimates systematically differed between studies, where smoking was controlled for or not. To evaluate which of the ratios $R_{1}$ and $R_{2}$ was most appropriate, we assessed which one explained a greater proportion of the variation when regressing the numerators on the denominators of the respective ratios, weighted by the inverse of the appropriate variances given above.

To apply the ratio estimates to external larger populations, ARLCs were calculated using method 1 , as $R_{1}$ times the number of mesothelioma deaths $\left(R_{1} \times O_{\mathrm{M}}\right)$, or using method 2, PAFs for lung cancer due to asbestos were calculated as $\left(1+0.1 \times O_{\text {all }} /\left(R_{2} \times O_{\mathrm{M}}\right)\right)^{-1}$. Using these results, we calculated PAF ranges for men aged 40-84 years during years 2001-2005, using the WHO mortality database for selected countries with mortality data coded to ICD-10 (WHOSIS Mortality Database ICD-10, 2009).

Population attributable fraction estimates were based firstly on ratio estimates as provided in Tables 1 and 2, and thereafter on ratio estimates corrected for smoking if smoking had not been accounted for. The correction applied was to reduce ratio estimates by $25 \%$ if smoking had not been taken into account, which corresponds to the degree of positive confounding in the lung cancer SMR, resulting from a smoking prevalence of $70 \%$ in the asbestos cohort compared with $50 \%$ in the general population and a smoking relative risk of 10 . This is likely to be an exaggerated correction and thus possibly underestimates ratio and PAF estimates.

\section{RESULTS}

\section{Ratio estimates}

Fifty five publications were included, from which 68 risk estimates were reported, 6 for crocidolite, 8 for crocidolite and chrysotile, 14 for predominantly chrysotile, 4 for amosite and 32 to mixed or unspecified asbestos fibres (Table 1, with an extended version in online Supplementary Table 1). In total, follow-up included over 67194 deaths, of which 1963 were from lung cancer and 1962 from mesothelioma. Most studies were conducted in North America or Europe, with only seven in other regions (Japan, Australia, China and South Africa). The two largest cohorts were the insulation workers' union of the United States and Canada $(n=17000)$, and the Great Britain Asbestos Survey of over 98000 registered asbestos workers (Selikoff and Seidman, 1991; Harding, 2010). Lung cancer SMRs for $78 \%$ of cohorts were not adjusted for smoking, other than in a few studies where internal analyses comparing exposed to unexposed subjects adjusted for smoking and in certain cohorts smoking prevalence of workers was noted to be comparable (or not) to that of the general population. We used the proportional mortality ratio in the British Asbestos survey in an attempt to get closer to a smoking-adjusted SMR (estimates 66 and 67).

Figure 1 plots absolute and relative lung cancer excess $v s$ mesotheliomas, that is, the numerator and denominators of ratios $R_{1}$ and $R_{2}$, by asbestos type. Note that axes for each subplot are on different scales, particularly for mesothelioma because of greatly varying mesothelioma-producing potential of the different fibres. The line on each plot corresponds to two excess lung cancer deaths per mesothelioma death, that is, this is the same ratio across graphs to aid comparison. 
Table I Crocidolite, chrysotile and amosite asbestos cohorts providing estimates of lung cancer and mesothelioma mortality, by asbestos type

Lung

cancer Lung

No. Cohort description (reference)

\% Smoking Total deaths cancer Mesothelioma Ratio Ratio

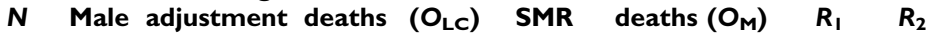

Crocidolite

Canadian gas mask canisters (McDonald and McDonald, 1978)

2 Nottingham gas masks, UK (Jones et al, 1980)

3 Leyland gas masks UK. Crocidolite, some chrysotile (Acheson et al,

199 NK

1982)

4 South African crocidolite mines (Sluis-Cremer et al, 1992)

5 Tuscany rail construction Italy (Battista et al, 1999)

6 Wittenoom mine/mill, Australia (Musk et al, 2008)

Chrysotile and crocidolite

7 Rochdale textile workers, UK. Chrysotile, 5\% crocidolite during 1932-1968 (Peto et al, 1985): men, 20+ years employment starting $<1933$

8 As for 7: Rochdale women, 10+ years employment after 1933

9 As for 7: Rochdale principal cohort, men first employed > 1933

I0 New Orleans cement Plant 2, USA (Hughes et al, 1987)

I Vocklabruck cement workers, Austria (Neuberger and Kundi, 1990) 2816 Both

12 Ferodo friction factory, UK. Predominantly chrysotile, crocidolite $13450 \quad 68$ use for a short period (Berry, 1994)

13 North Israel cement workers, $90 \%$ chrysotile, 10\% crocidolite (Tulchinsky et al, 1999)

I4 Norwegian asbestos cement factory. Chrysotile, 8\% amphiboles (Ulvestad et al, 2002)

Chrysotile (pure or predominantly)

I5 Blackburn gas masks, UK. Pure chrysotile (Acheson et al,

16 Wales cement workers. After 1936, chrysotile only. Before 1936, some crocidolite used (Thomas et al, 1982)

17 Connecticut friction industry, USA. Pure chrysotile ${ }^{c}$ (McDonald et al, 1984)

I8 Swedish cement workers. Chrysotile predominantly, < 1\% amosite/ crocidolite during short periods (Ohlson and Hogstedt, 1985)

19 Tamworth cement workers, UK. Chrysotile, with amosite used during 4 months out of 42 years (Gardner et al, 1986)

20 Balangero mine, Italy. Pure chrysotile (Piolatto et al, 1990)

21 Quebec, Canada: Quebec asbestos factory, chrysotile (Liddell et al, 1997)

22 As for 21: Thetford company 3, chrysotile and tremolite

23 As for 21: Thetford company 4, chrysotile+tremolite

24 As for 21: Quebec asbestos mine/mill, chrysotile

25 Chongqin asbestos workers, China. Pure chrysotile, tremolite content uncertain (Yano et al, 200I)

26 South Carolina textile workers, USA. Chrysotile, $<0.01 \%$ crocidolite (Hein et al, 2007)

27 North Carolina textile plants, USA. Predominantly chrysotile, with some amosite in plant 3 (Loomis et al, 2009)

28 Greece asbestos cement factory. Chrysotile with $0.5 \%$ amphibole contamination (Sichletidis et al, 2009)

29 Chrysotile miners, China (Wang $X$ et al, 20I I)

30 Chrysotile textile workers, China (Wang XR et al, 20। I). Mediumand high-exposed groups compared with low-exposed group

Amosite

31 Uxbridge amosite insulation, UK (Acheson et al, 1984)

32 Paterson amosite asbestos factory, NJ, USA (Seidman et al, 1986)

33 South African amosite mines (Sluis-Cremer et al, 1992)

34 Tyler pipe insulation, amosite, TX, USA (Levin et al, 1998)

$3057 \quad 100$

$545 \quad 100$

$570 \quad 0$

$1970 \quad 100$

$3531 \quad 100$

$1176 \quad 100$

$2167 \quad 70$

$1058 \quad 100$

792100

$4732 \quad 100$

$368 \quad 100$

$4503 \quad 100$

$515 \quad 100$

$3072 \quad 59$

$5770 \quad 69$

$317 \quad 100$

$1080 \quad 100$

$461 \quad 100$

$4820 \quad 100$

$820 \quad 100$

$3212 \quad 100$

$1130 \quad 100$
N

$N$

$N$

$N$

N

N

$N$

$N$

C

N

N

N

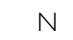

$N$

177

351

803

N

C

$$
220
$$

N

$$
486
$$

427

508

3080

267

2924

132

1961

2583

52

343

207

tio

$\begin{array}{rr}7 & 2.92 \\ 12 & 1.90 \\ 13 & 2.10 \\ & \\ 27 & 2.03 \\ 26 & 1.24 \\ 281 & 2.60\end{array}$

$\begin{array}{rll}9 & 0.5 & 0.9 \\ 17 & 0.3 & 0.8 \\ 5 & 1.4 & 4.6 \\ & & \\ 20 & 0.7 & 2.0 \\ 5 & 1.0 & 0.9 \\ 222 & 0.8 & 1.5\end{array}$

0.9

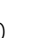

.5


Table 2 Cohorts with exposure to mixed asbestos fibres: lung cancer and mesothelioma mortality and ratio estimates

\begin{tabular}{|c|c|c|c|c|c|c|c|c|c|c|}
\hline No. & Cohort description (reference) & $\mathbf{N}$ & $\begin{array}{c}\% \\
\text { Male }\end{array}$ & $\begin{array}{l}\text { Smoking } \\
\text { adjustment }\end{array}$ & $\begin{array}{l}\text { Total } \\
\text { deaths }\end{array}$ & $\begin{array}{c}\text { Lung } \\
\text { cancer } \\
\text { deaths } \\
\left(O_{L C}\right)\end{array}$ & $\begin{array}{c}\text { Lung } \\
\text { cancer } \\
\text { SMR }\end{array}$ & $\begin{array}{l}\text { Mesothelioma } \\
\text { deaths }\left(O_{M}\right)\end{array}$ & $\begin{array}{c}\text { Ratio } \\
R_{\mathbf{I}}\end{array}$ & $\begin{array}{c}\text { Ratio } \\
\mathbf{R}_{\mathbf{2}}\end{array}$ \\
\hline \multicolumn{11}{|c|}{ Mixed (or unspecified) asbestos types } \\
\hline 37 & Belgian asbestos-cement factory (Lacquet et al, 1980) & 1973 & 100 & $\mathrm{~N}$ & 201 & 17 & 0.99 & I & -0.2 & -0.3 \\
\hline 38 & Devonport dockyard, UK (Rossiter and Coles, 1980) & 6292 & 100 & $\mathrm{~N}$ & 1043 & 84 & 0.84 & 31 & -0.5 & -0.5 \\
\hline 39 & $\begin{array}{l}\text { Danish asbestos-cement factory (Clemmesen and Hjalgrim-Jensen, } \\
\text { 1981) }\end{array}$ & 6372 & 100 & N & - & 47 & 1.72 & 3 & 6.6 & - \\
\hline 40 & $\begin{array}{l}\text { Pennsylvania textile, USA. Mostly chrysotile, some amosite, small } \\
\text { amounts crocidolite (McDonald et al, 1983) }\end{array}$ & 4137 & 100 & $\mathrm{~N}$ & 1392 & 57 & 1.05 & 13 & 0.2 & 0.5 \\
\hline 41 & Ontario cement workers, Canada (Finkelstein, 1984) & 535 & 100 & $\mathrm{~N}$ & 108 & 26 & 4.89 & 17 & 1.2 & 1.6 \\
\hline 42 & Swedish rail maintenance (Ohlson et al, 1984) & 3297 & 100 & $\mathrm{~N}$ & 925 & 37 & 1.16 & 5 & 1.0 & 3.0 \\
\hline 43 & Pearl Harbour naval shipyard, USA (Kolonel et al, 1985) & 5191 & 100 & C & 668 & 122 & 1.09 & 8 & 1.2 & 0.7 \\
\hline \multirow[t]{2}{*}{44} & $\begin{array}{l}\text { Paray-Le-Monial cement factory, France (Alies-Patin and Valleron, } \\
\text { 1985) }\end{array}$ & 1506 & 100 & N & 206 & 12 & 2.18 & 4 & 1.6 & 5.8 \\
\hline & German asbestos workers (Woitowitz et al, 1986) & & NS & N & & & & & & \\
\hline 45 & (a) Exposed before 1972 only & 655 & & & 71 & 12 & 4.62 & 6 & 1.6 & 3.6 \\
\hline 46 & (b) Exposed before and after 1972 & 3070 & & & 185 & 26 & 1.70 & 6 & 1.8 & 2.0 \\
\hline 47 & Gothenburg shipyard, Sweden (Sanden and Jarvholm, 1987) & 3787 & 100 & $\mathrm{~N}$ & - & 11 & 1.12 & 4 & 0.3 & - \\
\hline 48 & Mixed industry, Johns Manville retirees, USA (Enterline et al, 1987) & 1074 & 100 & $\mathrm{~N}$ & 944 & 77 & 2.71 & 8 & 6.1 & 20.2 \\
\hline 49 & $\begin{array}{l}\text { Cement, New Orleans Plant I, USA. Primarily chrysotile, irregular } \\
\text { use of amosite and crocidolite (Hughes et al, 1987) }\end{array}$ & 1898 & 100 & C & 477 & 47 & 1.17 & 2 & 3.4 & 4.0 \\
\hline 50 & Finnish shipyard workers (Tola et al, 1988) & 7775 & 100 & C & - & 227 & 1.18 & । & 34.9 & - \\
\hline 51 & Southern Sweden cement workers (Albin et al, 1990) & 1465 & 100 & N & 592 & 35 & 1.80 & 13 & 1.2 & 3.5 \\
\hline 52 & $\begin{array}{l}\text { Asbestos insulation union, USA-Canada (Selikoff and Seidman, } \\
\text { |99|) }\end{array}$ & 17800 & 100 & $N$ & 4951 & 1168 & 4.35 & 458 & 2.0 & 2.6 \\
\hline 53 & Italian rail carriage construction (Menegozzo et al, 1993) & 1534 & 100 & $\mathrm{~N}$ & 194 & 28 & 1.45 & 5 & 1.7 & 1.6 \\
\hline 54 & $\begin{array}{l}\text { Emilia Romagna cement factory, Italy. Chrysotile and 5-50\% } \\
\text { crocidolite (Giaroli et al, 1994) }\end{array}$ & 3341 & 100 & $N$ & 274 & 33 & 1.24 & 6 & I.I & 1.1 \\
\hline 55 & $\begin{array}{l}\text { Danish Eternit cement factory, } 90 \% \text { chrysotile, amosite and small } \\
\text { amounts crocidolite (Raffn et al, 1996) }\end{array}$ & 7996 & 100 & C & 1305 & 104 & 1.83 & 10 & 4.7 & 10.3 \\
\hline 56 & East London asbestos workers UK (Berry et al, 2000) of which: & 5100 & & $\mathrm{~N}$ & 1237 & 233 & 3.03 & 100 & 1.6 & 2.0 \\
\hline 57 & As for 56: East London laggers & 1400 & 100 & $\mathrm{~N}$ & - & 38 & 3.67 & 13 & 2.1 & - \\
\hline 58 & As for 56: East London men & 3000 & 100 & $\mathrm{~N}$ & - & 157 & 2.55 & 60 & 1.6 & - \\
\hline 59 & As for 56: East London women & 700 & 0 & $\mathrm{~N}$ & - & 37 & 7.46 & 25 & 1.3 & - \\
\hline 60 & Genoa shipyard, Italy (Puntoni et al, 200 I) & 3984 & 100 & C & 2376 & 298 & 1.77 & 60 & 2.2 & 2.8 \\
\hline 61 & Lithuania cement, Naujoji Akmeme Lithuania (Smailyte et al, 2004) & 2498 & 69 & $\mathrm{~N}$ & 450 & 38 & 1.40 & I & 10.9 & 17.5 \\
\hline 62 & Ontario pipe trade, Canada (Finkelstein and Verma, 2004) & 25285 & 100 & $\mathrm{~N}$ & 2876 & 393 & 1.23 & 8 & 9.1 & 8.0 \\
\hline 63 & US Coast Guard shipyard workers (Krstev et al, 2007) & 4702 & 94 & $\mathrm{~N}$ & 3331 & 314 & 1.26 & 6 & 11.0 & 14.4 \\
\hline 64 & $\begin{array}{l}\text { Grugliasco textile Italy. Mixed asbestos with crocidolite (Pira et al, } \\
\text { 2007) }\end{array}$ & 1966 & 45 & $N$ & 730 & 109 & 3.11 & 68 & 1.1 & 1.8 \\
\hline 65 & $\begin{array}{l}\text { Breda Pistoia railway rolling factory, Italy (Gasparrini et al, 2008) } \\
\text { Great Britain Asbestos Survey (Harding, 2010) }\end{array}$ & 1146 & 100 & $N$ & 1080 & 132 & 1.36 & 16 & 2.2 & 2.3 \\
\hline 66 & Men & 94403 & 100 & C & 14677 & 1802 & $1.28^{\mathrm{a}}$ & 631 & 0.6 & 0.6 \\
\hline 67 & Women & 4509 & 0 & & 880 & 84 & $1.29^{\mathrm{a}}$ & 18 & I.I & 1.4 \\
\hline 68 & $\begin{array}{l}\text { Japanese shipyard (laggers and boiler repairers) (Tomioka et al, } \\
2011 \text { ) }\end{array}$ & 249 & 100 & $C$ & 158 & 15 & 1.97 & I & 7.4 & 14.5 \\
\hline
\end{tabular}

Abbreviations: $A=$ adjusted; $C=$ smoking prevalence in cohort comparable to the general population; $N=$ none or not mentioned; $S M R=$ standardised mortality ratio. aproportional mortality ratio reported rather than SMR.

Crocidolite and crocidolite plus chrysotile In the six crocidoliteexposed cohorts, workers experienced increased lung cancer mortality, of the order of a two-to three-fold increase (pooled SMR 2.0, Table 3), and increased mesothelioma risk, with mesothelioma deaths contributing to a median of 93.2 per thousand deaths (range 23-217). In all but two smaller cohorts, there were less or equivalent numbers of excess lung cancers compared with mesothelioma deaths, giving a combined $R_{1}$ estimate of 0.71 ARLC deaths per mesothelioma death (Table 3, Figure 2). The combined estimate of ratio $R_{2}$ suggests a $1.2 \%$ increase in lung cancer deaths $(\mathrm{PAF}=1.2 \%)$ associated with crocidolite for every mesothelioma death in 1000 deaths.

For cohorts with a mixture of chrysotile and some crocidolite, mesothelioma risk was also raised but to a lesser extent than for pure crocidolite (7.6 mesothelioma deaths per 1000 non-asbestosrelated deaths). Lung cancer risk was increased (SMR 1.58), varying from no lung cancer excess in the Ferodo friction factory (estimate 12) to increases of over three-fold (Table 1 and Figure 2). These combined to give an overall $R_{1}$ estimate of 1.44 excess lung cancers per mesothelioma death (Table 3 ).

Chrysotile Chrysotile cohorts had a wider range of estimates, resulting from little correlation between excess lung cancers and mesotheliomas (Figures 1 and 2). Almost all SMRs for lung cancer were between 1 and 2, with two notable exceptions of two Chinese mines (estimates 25 and 29). In 14 of 16 estimates, the number of excess lung cancer deaths was more than the number of mesothelioma deaths (Figure 2); an average $R_{1}$ of 6.1 excess lung cancers per mesothelioma death (Table 3 ). This much larger ratio, compared with that for crocidolite, arises mainly from a much smaller associated mesothelioma risk, including four cohorts that had no mesothelioma deaths (estimates 17, 18, 28 and 29, Table 1). 

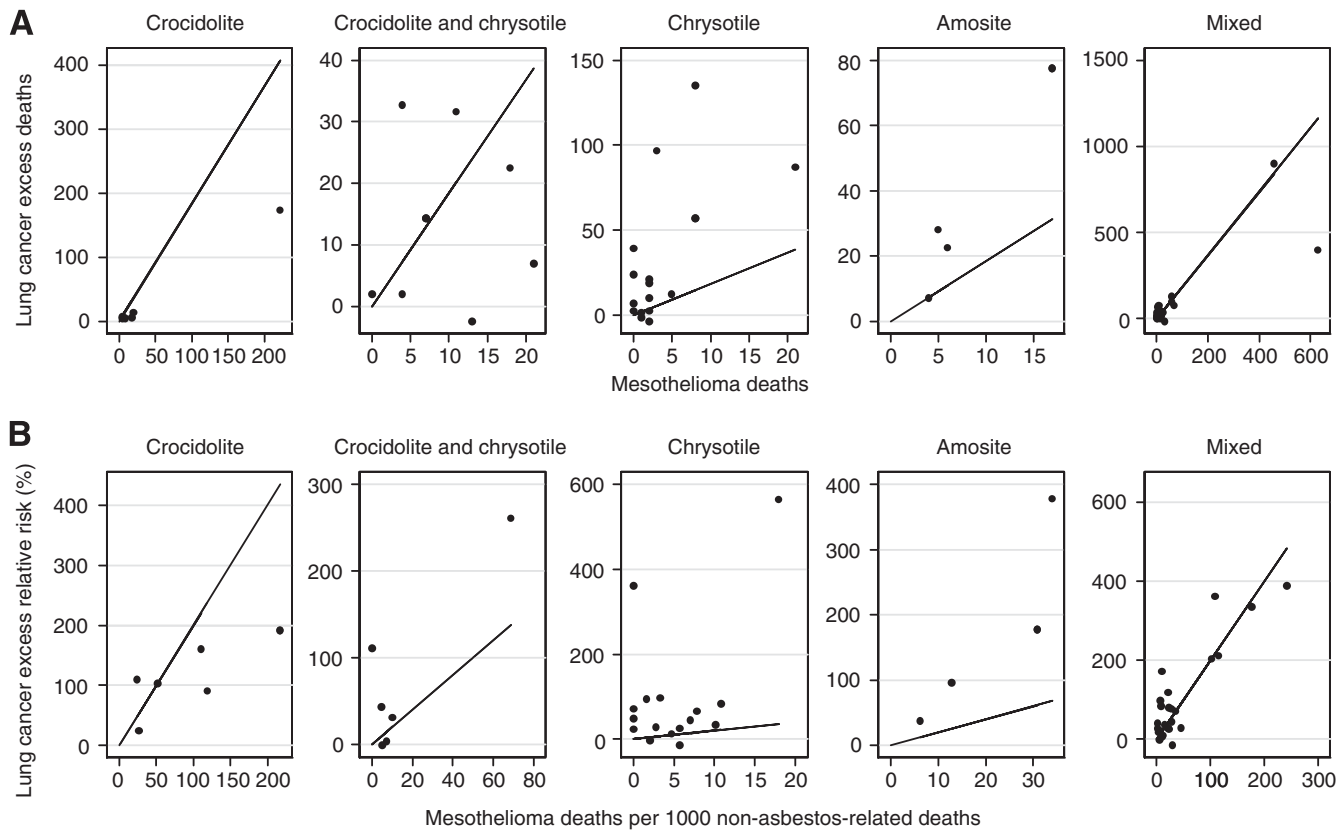

Figure I (A) Ratio I components, absolute excess lung cancer excess deaths vs mesothelioma deaths, by asbestos type. (B) Ratio 2 components, lung cancer excess relative risk (\%) vs mesothelioma deaths per 1000 non-asbestos-related deaths, by asbestos type. Note that graphs are not to the same scale. The reference line on each sub-graph corresponds to the same ratio estimate (average values for mixed fibres from Table 3); thus, the distribution of points about this line can be compared across subgraphs.

Table 3 Estimated ratios by asbestos fibre type for (i) absolute excess lung cancer deaths to mesothelioma deaths and (ii) excess lung cancer percentage to mesothelioma deaths per 1000 non-asbestos-related deaths

\begin{tabular}{|c|c|c|c|c|c|c|}
\hline \multirow{2}{*}{$\begin{array}{l}\text { Asbestos type } \\
\text { (no. of estimates) }\end{array}$} & \multirow{2}{*}{$\begin{array}{l}\text { Lung cancer } \\
\text { mortality SMR } \\
\text { Mean }(95 \% \mathrm{CI})\end{array}$} & \multirow{2}{*}{$\begin{array}{l}\text { Mesothelioma deaths per } 1000 \\
\text { non-asbestos-related deaths }\end{array}$} & \multicolumn{2}{|c|}{$\begin{array}{c}\text { Ratio } R_{1} \text { excess lung cancers } \\
\text { per mesothelioma death }\end{array}$} & \multicolumn{2}{|c|}{$\begin{array}{l}\text { Ratio } R_{2} \text { excess lung cancer }(\%) \\
\text { for every mesothelioma death in } \\
1000 \text { non-asbestos-related deaths }\end{array}$} \\
\hline & & & Median (IQR) & Mean $(95 \% \mathrm{Cl})$ & Median (IQR) & Mean $(95 \% \mathrm{Cl})$ \\
\hline Crocidolite (6) & $2.04(1.55,2.69)$ & 93.2 & $0.7(0.5,1.1)$ & $\begin{aligned} & \cup 0.7(0.5,1.0) \\
& \text { SA } 0.6(0.3,0.9)\end{aligned}$ & $1.2(0.9,2.6)$ & $\begin{aligned} \cup & 1.4(1.0,2.1) \\
\text { SA } & 1.2(0.8,1.8)\end{aligned}$ \\
\hline $\begin{array}{l}\text { Chrysotile and } \\
\text { Crocidolite (8) }\end{array}$ & $1.58(1.19,2.08)$ & 7.6 & $1.7(0.4,6.8)$ & $\begin{aligned} \cup & 1.4(0.6,3.5) \\
\text { SA } & 1.2(0.5,2.9)\end{aligned}$ & $3.4(0.4,9.4)$ & $\begin{aligned} & \cup 2.8(1.0,7.5) \\
& \text { SA } 2.4(0.9,6.3)\end{aligned}$ \\
\hline Amosite (4) & $2.48(1.42,4.33)$ & 18.6 & 4.I $(2.3,5.3)$ & $\begin{aligned} & \cup 4.0(2.8,5.8) \\
& \text { SA } 3.0(2.1,4.4)\end{aligned}$ & $6.8(5.8,10.2)$ & $\begin{aligned} & \cup 8.4(5.9,11 \\
& \text { SA } 6.3(4.5,8.8)\end{aligned}$ \\
\hline Mixed (3I) & $1.77(1.44,2.20)$ & 42.2 & $1.6(1.1,4.4)$ & $\begin{aligned} \cup & 1.9(1.4,2.6) \\
\text { SA } & 1.5(1.1,2.0)\end{aligned}$ & $2.0(1.2,4.9)$ & $\begin{aligned} & \cup 2.8(1.9,4.2) \\
& \text { SA } 2.2(1.6,3.2)\end{aligned}$ \\
\hline
\end{tabular}

Abbreviations: $\mathrm{Cl}=$ confidence interval; $\mathrm{IQR}=$ interquartile range (25th, 75th percentiles); $\mathrm{SA}=$ smoking adjusted; $\mathrm{U}=$ unadjusted. Means and their $95 \% \mathrm{Cl}$ calculated from a random effects meta-analysis. $I^{2}$ percentages (\% of variability this is due to between-study difference) (heterogeneity $P$-value) for crocidolite, chrysotile+crocidolite, chrysotile, amosite and mixed fibres, respectively, are: for unadjusted $R_{1}: 29 \%(P=0.22), 85 \%(P<0.01), 53 \%(P=0.007), 0 \%(P=0.39), 94 \%(P<0.001)$; for $R_{2}: 52 \%(P=0.06)$, 8I\% ( $P<0.00 \mathrm{I}), 74 \%(P<0.00 \mathrm{I}), 0 \%(P=0.68), 97 \%(P<0.00 \mathrm{I})$.

The small denominator and wide range makes ratio estimates of excess lung cancers to mesotheliomas large, but imprecise for chrysotile.

Amphiboles In the follow-up of four amosite cohorts, there was a marked correlation between lung cancer SMR and mesothelioma. The combined SMR for lung cancer was 2.5, slightly stronger than that for crocidolite and thus, with a mesothelioma risk approximately one-fifth of that for crocidolite (18 vs 93 mesotheliomas per 1000 deaths in amosite and crocidolite, respectively, Table 3), ratio $R_{1}$ was much higher at 4 excess lung cancers per mesothelioma death (Table 3 ). Corresponding $R_{2}$ estimates suggest there was between a $6 \%$ and $10 \%$ increase in lung cancer deaths for every mesothelioma death in 1000 deaths. The largest contributing study was the Paterson amosite factory in New Jersey (estimate 32), where both a large number of mesotheliomas (17 in 820 workers) and a very large excess lung cancer mortality were observed (SMR 4.8) (Seidman et al, 1986). In the only cohort with anthophyllite exposure (estimate 35 ), there were 12.5 excess lung cancers per mesothelioma death (Meurman et al, 1994).

Mixed asbestos types For the majority of cohorts asbestos exposure was mixed and their ratio estimates lay between the corresponding values for pure asbestos fibres. The summary SMR for lung cancer was 1.77 (95\% CI 1.44, 2.20), which was less than that for crocidolite or amosite, but larger than that for chrysotile. 


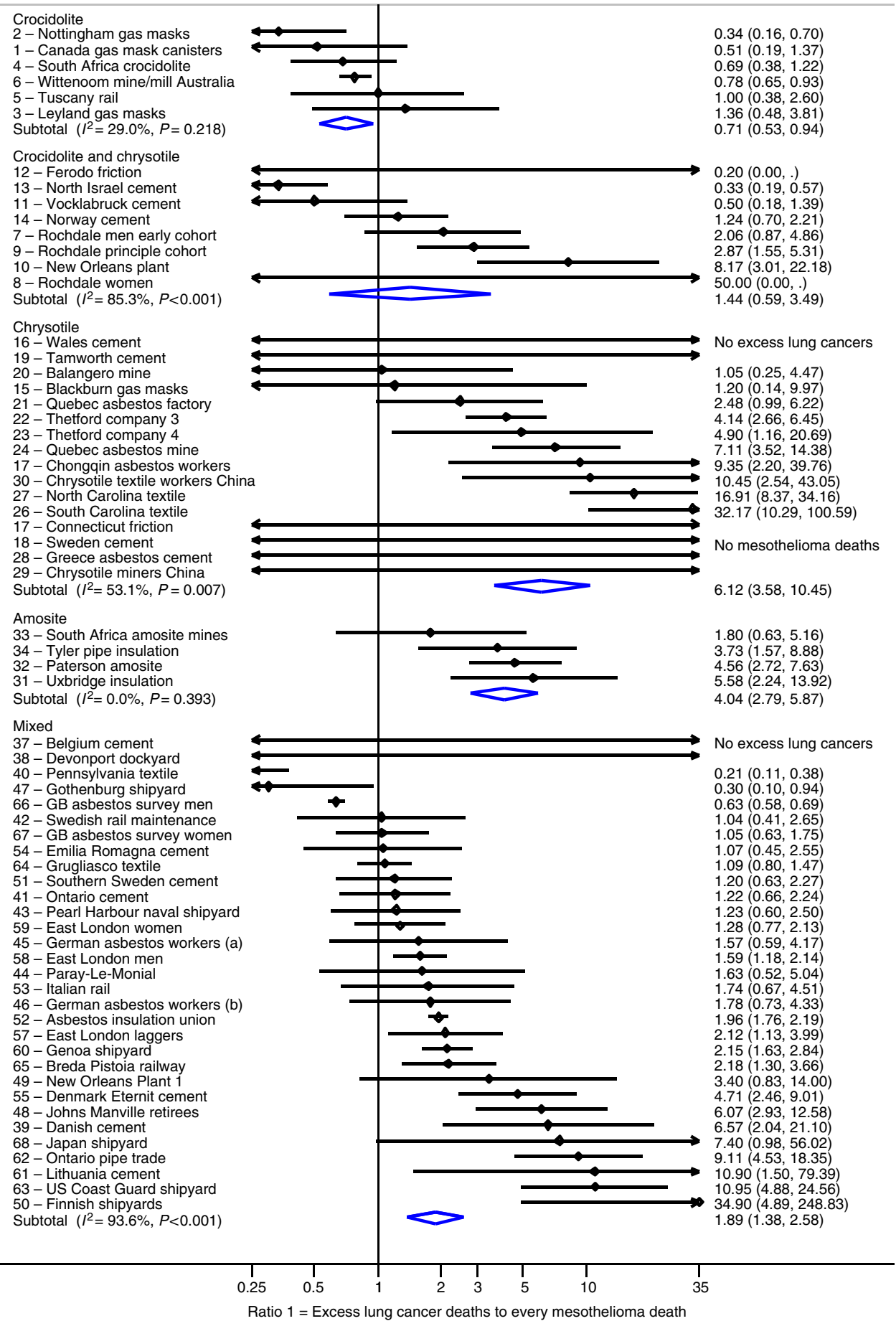

Figure 2 Ratio of asbestos-related lung cancers to mesothelioma deaths, study-specific and random effects combined estimates by asbestos fibre type. Estimates of the ratio of excess lung cancer deaths to every mesothelioma death $\left(R_{I}\right)$ in each study, by asbestos fibre type. $I^{2}$ represents the percentage of the variation in the study-specific estimates that are due to true heterogeneity rather than due to chance.

Mesothelioma deaths as a proportion of total mortality were half that for crocidolite, but higher than chrysotile or amosite (Table 3). There were between one and three excess lung cancers for every mesothelioma death in half of the cohorts, but the estimate in the two largest cohorts were very different, at 0.6 in men in the Great Britain Asbestos Survey and 2.0 in US and Canadian insulation workers (estimates 55 and 66, Table 1). For all mixed asbestos cohorts combined, there were $1.9(95 \%$ CI $1.4,2.6)$ excess lung cancer deaths for every mesothelioma death, although with large heterogeneity.

Comparison of the two ratio estimates The percentage of the variance explained by regression of the contributing numerator on denominator was higher for $R_{1}$ (>95\%) than for $R_{2}$ for crocidolite, crocidolite + chrysotile and for mixed asbestos cohorts, but was higher for $R_{2}$ than $R_{1}$ for chrysotile and amosite cohorts. 


\section{Population attributable fractions in men}

Table 4 provides, for 20 countries with large mesothelioma proportional mortality, PAFs (\%) of male lung cancer deaths due to asbestos estimated using the crude and smoking-adjusted estimates of ratios $R_{1}$ and $R_{2}$ for exposure to mixed asbestos fibres, and smoking-adjusted ratios for crocidolite. The smoking adjustment (derived from 20\% higher cohort smoking prevalence than the general population) is likely to underestimate ratios and PAFs, and can be considered a lower limit. In the countries listed, mesothelioma deaths ranged from 1 to 9 per 1000 deaths. If the ratio of ARLC to mesothelioma deaths were exactly 1 , then mesothelioma deaths as a percentage of lung cancer deaths (ranging from $1 \%$ to $9 \%$ for these countries) would be the PAF (\%) of lung cancer due to asbestos. For Australia, at the top of the table with the highest percentage of deaths from mesothelioma, using ratio estimates for crocidolite, we estimated that between $5.4 \%$ and $8.6 \%$ of lung cancer deaths in men are asbestos-related, based on $R_{1}$ and $R_{2}$, respectively. Similarly in the United Kingdom, New Zealand, South Africa and the Netherlands, where crocidolite was used among other asbestos fibres, PAFs ranged between $4 \%$ and $7 \%$. For South Africa calculations based on $R_{1}$ estimates (PAF $6.7-8.4 \%$ for mixed fibres, $2.7 \%$ for crocidolite) are more suitable as total background mortality, which is incorporated into $R_{2}$-based estimates, is particularly high in this country during the HIV era. Applying the ratios for mixed asbestos exposures, PAFs for other countries lie between 3\% and 7\% using both ratio methods of estimation. For the United States, the estimated PAF in men was estimated to be $3.2-4.0 \%$ for mixed asbestos ( $R_{1}$ estimates).

\section{DISCUSSION}

The ratios of ARLCs to mesotheliomas fall into three categories: (1) pure amphibole or mixed exposures causing high lung cancer risks and ARLC/mesothelioma ratios ranging from $<1$ for crocidolite, 1.4 to 2.5 for mixed types, to 4 or more for amosite and anthophyllite; (2) heavy prolonged chrysotile exposures causing high lung cancer risks and ARLC: mesothelioma ratios of the order of 10; and (3) shorter or less heavy chrysotile exposures causing lower lung cancer risks and little mesothelioma, between which there was little correlation and thus calculation of excess lung cancers from mesothelioma deaths after chrysotile exposure would not be reliable. Thus for all asbestos types other than crocidolite, the ARLC is larger than that for mesothelioma, but the low ARLC to mesothelioma ratio for crocidolite (0.71) does not imply that the lung cancer risk is small, only that it is slightly smaller than the high mesothelioma risk.

The ARLC: mesothelioma ratio in chrysotile cohorts may be dominated by two large errors. First, the lung cancer excess depends critically on the rates on which the SMR is based. Second, it seems likely that many of the mesotheliomas in such cohorts are actually due to amphibole exposure. These points are illustrated by the chrysotile miners and millers in Quebec (estimates 21-24). Their ARLC: mesothelioma ratio varied substantially, from 3.3 (22 mesotheliomas; 423 lung cancers, SMR 1.21) for cumulative exposures below 300 million particles per cubic foot (mpcf)-years to 31 (1 mesothelioma; 47 lung cancers, SMR 2.97) above 1000 mpcf-years. The lung cancer excess above 1000 mpcf-years is affected little by the choice of rates, but below 300 mpcf-years the lung cancer excess could be doubled or reduced to zero by a $20 \%$ change in expected rates. Furthermore, many mesotheliomas occurring in asbestos that is predominantly chrysotile may actually be due to other asbestos types. McDonald et al (1997) argued that the mesotheliomas among chrysotile miners and millers in Quebec were caused either by amphibole exposure elsewhere or by the tremolite that contaminated most Canadian chrysotile. Analysis of 22 lung samples from mesotheliomas in this cohort showed that 6 contained substantial amounts of crocidolite, and only 2 contained more chrysotile than tremolite despite their much heavier exposure to chrysotile. Tremolite, similarly to crocidolite

Table 4 Estimates of population attributable fractions (\%) ranges of lung cancer in men due to exposure to mixed asbestos and crocidolite asbestos fibres

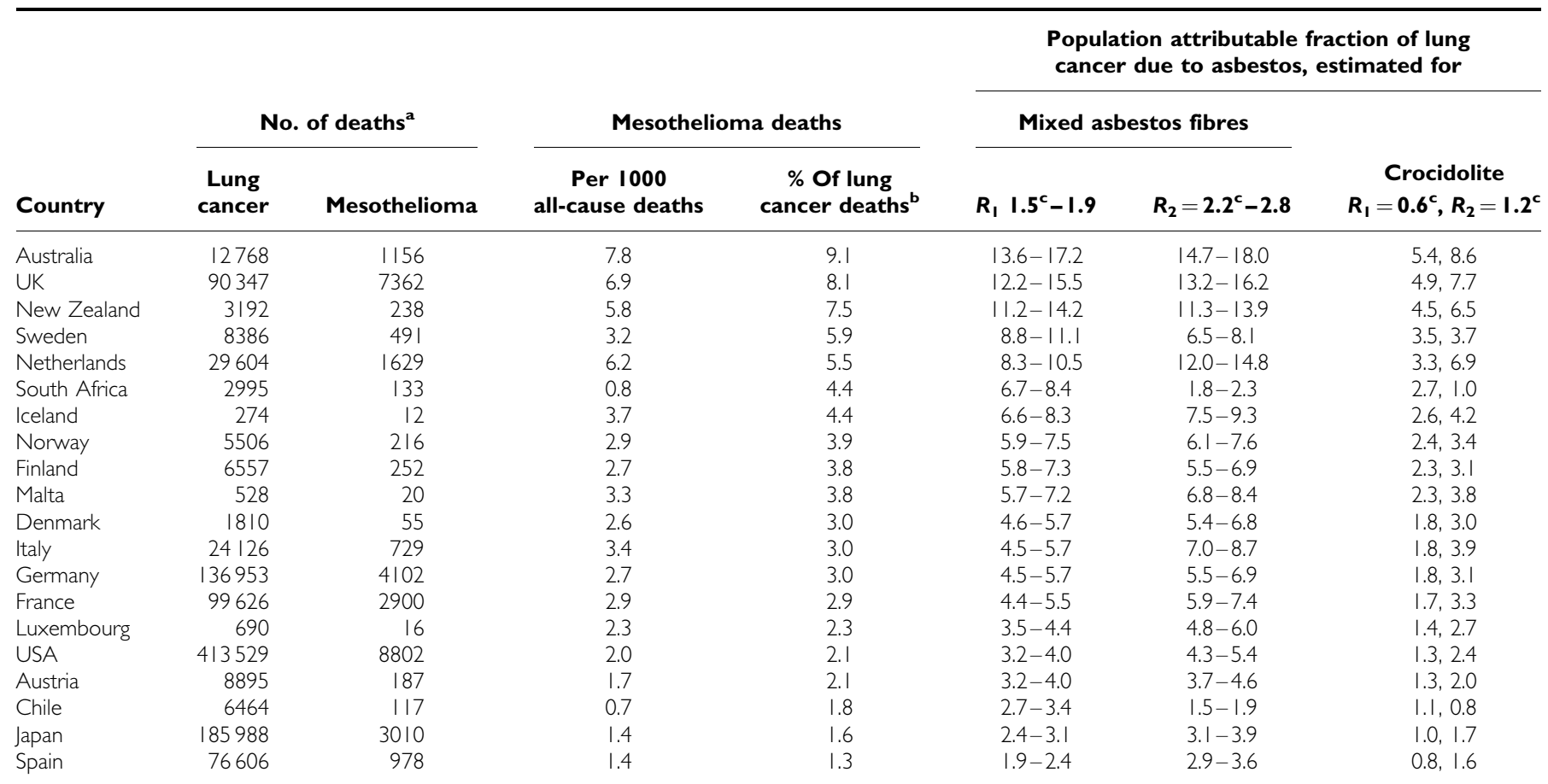

${ }^{\mathrm{a} B a s e d}$ on the number of mesothelioma deaths in 1000 deaths, men aged 40-84, years 200I-2005, for countries using ICD 10 (WHO mortality data). ${ }^{b}$ Note that if there were one asbestos-related lung cancer for every mesothelioma death, this percentage would be the PAF (\%) of lung cancer due to asbestos. The ratio and thus PAFs are likely to be higher. ${ }^{~}$ Corrected for confounding by smoking of up to $20 \%$ higher cohort smoking rates compared with the general population. 
and amosite, is an amphibole that is cleared less rapidly from the lung than chrysotile. The vermiculite miners in Montana were included on this basis as vermiculite contains tremolite. Nevertheless, irrespective of the contribution of tremolite, it seems that prolonged heavy exposure to chrysotile causes a much larger excess of lung cancer than of mesothelioma.

\section{Heterogeneity in ratio estimates within and between cohorts}

Neither ratio $R_{1}$ or $R_{2}$ appeared to be more constant across all cohorts. Although it was expected that $R_{2}$ would more appropriately account for differential background lung cancer incidence rates, and thus be a more constant ratio, its denominator - ideally an age-adjusted mesothelioma mortality rate could not be calculated - was mesothelioma proportional mortality and thus was additionally affected by differential background mortality rates. Nonetheless, PAF estimates using either ratio did not differ hugely.

We have considered the effect of fibre type on ratios; however, several other factors, discussed below, will affect within and between study ratio estimates. Stratifying by each factor could not be conducted owing to lack of data. The summary ratios provided here thus better characterise the overall ARLC-mesothelioma relationship across exposure circumstances and over a long period of time, and do not serve to precisely quantify lung cancer excess in a short time period.

(i) Dose-response relationship: Most formal risk assessment analyses assume that the relative risk for lung cancer is increased by each brief period of asbestos exposure in proportion to dose (intensity times duration), whereas the increase in the absolute mesothelioma rate is proportional to the dose weighted by the square or cube of latency. Such models imply that prolonged exposure beginning in middle age will cause a ratio of ARLC to mesothelioma more than 10 times greater than brief exposure at age 20 years (Peto et al, 1985). The ratio is thus age-dependent and affected by differences in the length of follow-up between studies. Exposure intensity also varies between and within cohorts, for example, if factory ventilation systems improve.

(ii) Death certificate reporting bias: Inaccurate recording of deaths may lead to possible overestimation of ratios, as shown by an autopsy-death certificate comparison in which false-negative mesotheliomas were likely to be recorded as lung cancers (Delendi et al, 1991). Special efforts to capture all mesothelioma deaths from medical records and mesothelioma registries would have reduced this bias here and mesothelioma-reporting accuracy should improve over time with the use of ICD-10.

(iii) Overall mortality rates: Although the use of a relative effect on lung cancer has been captured in $R_{2}$, its denominator would ideally be an age-standardised mesothelioma mortality rate. Instead the mesotheliomas per 1000 deaths are affected by changes in the overall risk of death. Mesothelioma proportional mortality will be higher in cohorts with lower mortality.

(iv) Confounding/effect modification by smoking and other lung carcinogens: Ratio estimates hinge on the assumption that SMRs for lung cancer are unbiased. Several cohorts specifically adjusted for smoking (estimates $11,25,29,30,68$ ) and in some others estimates of smoking prevalence in subsets suggest that they were similar to that of the general population (estimates 43, 50,51). Use of the PMR (1.28) rather than the SMR (1.89) for lung cancer was intended to reduce confounding by smoking (estimates 66, 67; Harding, 2010). The extent to which bias may be present in other cohorts depends on the social-class smoking gradient. Two recent cohorts commented on a higher smoking prevalence (estimates 61,62 ) than in the general population, which may explain their high ratios. In addition, asbestos has a stronger effect on lung cancer in smokers than non-smokers, whereas smoking has little or no effect on mesothelioma. Thus, higher baseline lung cancer mortality rates may explain the higher ratios observed in United States and the European cohorts than in Israel (estimate 13, with a low lung cancer mortality rate; Tulchinsky et al, 1999). The great majority of cohorts included here were from Europe, the United States and Canada, where asbestos exposure occurred predominantly during the 1940s to 1970s when smoking prevalence was high. Estimates for Ontario pipe traders and two cohorts of shipyard workers (cohorts 50 and 63) may be overestimated if these workers also had exposure to other lung carcinogens, such as lead, chromium, cadmium and diesel exhaust.

\section{Population-level inferences}

For countries with the highest percent deaths from mesothelioma in men, estimates of the lung cancer PAF due to asbestos were between 3\% and $8 \%$ for 2001-2005. In almost all of these countries, lung cancer made up $20-30 \%$ of cancer deaths, thus even $3-8 \%$ of this is a considerable contribution to the most common cause of cancer mortality in men in these settings. A few previous lung cancer-asbestos PAF estimates have been made. For the United Kingdom, the British Asbestos Survey included here had an $R_{1}$ value of 0.6 , much lower than the other mixed asbestos cohorts. Darnton et al (2006) obtained a similar estimate $\left(R_{1}\right.$ between 0.7 and 1$)$ from a population-based analysis of the relationship between lung cancer and mesothelioma PMRs in men in 131 occupational groups, adjusting for smoking, and a PAF of $2 \%$ to $3 \%$. This is approximately half of the estimate found here $(4.9 \%$ to $7.7 \%$ using crocidolite ratios, from Table 3$)$, and the difference may be because their estimate was for a longer earlier period (1980-2000) than the current estimates (for 2001-2005), during which time mesotheliomas have increased as a percentage of lung cancer deaths (from $3.8 \%$ to $8.1 \%$ ). However, as amosite was a major cause of mesothelioma in the United Kingdom (Rake et al, 2009), the lung cancer excess in the United Kingdom would be expected to be even higher. For Italy, Marinaccio et al (2008) used a model-based approach to estimate the ARLC burden in men in 1980-2001 and found PAFs for lung cancer mortality of between $1.6 \%$ and $3.7 \%$, that is, a ratio $\left(R_{1}\right)$ of between 0.68 and 1.37 excess lung cancers per mesothelioma. These estimates are similar to those of Darnton et al (2006), and also suggest a slightly lower ratio of ARLCs to mesotheliomas than that based on our estimated ratios from mixed asbestos cohorts. In the United States, where amphiboles constituted a much smaller proportion of asbestos consumption than in Europe, estimates of the male lung cancer PAF for asbestos were $6 \%$ to $8 \%$ in the 1990 s (Nicholson et al, 1982; Morabia et al, 1992), slightly higher than the estimate of 4.0-5.0\% here. In Finland, where anthophyllite was mined extensively, 2.7 mesothelioma deaths per 1000 would lead to a PAF for lung cancer of over $11 \%$ (using $R_{2}=4.4$ ), consistent with Nurminen and Karjalainen (2001) estimate of $14 \%$. Attempts to estimate ARLCs at a population level should be made with additional caveats. The majority of asbestos exposures at the population level may be of lower intensity and for longer durations, and the largest exposed groups may not be represented in asbestos cohorts, for example, construction workers and carpenters in the United Kingdom (Rake et al, 2009).

The asbestos-related cancer burden today is predominantly in Europe, North America, Australia, Japan, South Africa and parts of South America. However, the highest current consumption and exposure, and thus future burden, is in China, Russia, India, Kazakhstan, Ukraine, Thailand, Brazil and Iran. Exposure today is predominantly to chrysotile, either in a pure form or naturally 
contaminated by tremolite. The ratios presented demonstrate that the mesothelioma-producing potential of chrysotile is low and thus the number of mesothelioma deaths will be too unstable to be used to estimate the lung cancers caused by it. Critically, few mesotheliomas associated with chrysotile exposure cannot be used to imply a small asbestos-related lung cancer burden. The major effect of the continuing use of this carcinogen will be on lung cancer. High smoking rates in men (e.g., $70 \%$ in Russia, $61 \%$ in China (World Health Organization, 2008)) in these countries will amplify the associated lung cancer burden. There is thus an urgent need for limiting exposure through strict regulation of asbestos use, and encouragement of smoking cessation to reduce mortality among formerly exposed workers.

\section{REFERENCES}

Acheson ED, Gardner MJ, Pippard EC, Grime LP (1982) Mortality of two groups of women who manufactured gas masks from chrysotile and crocidolite asbestos: a 40-year follow-up. $\mathrm{Br}$ J Ind Med 39: 344-348

Acheson ED, Gardner MJ, Winter PD, Bennett C (1984) Cancer in a factory using amosite asbestos. Int J Epidemiol 13: 3-10

Albin M, Jakobsson K, Attewell R, Johansson L, Welinder H (1990) Mortality and cancer morbidity in cohorts of asbestos cement workers and referents. $\mathrm{Br} J$ Ind Med 47: 602-610

Alies-Patin AM, Valleron AJ (1985) Mortality of workers in a French asbestos cement factory 1940-1982. Br J Ind Med 42: 219-225

Battista G, Belli S, Comba P, Fiumalbi C, Grignoli M, Loi F, Orsi D, Paredes I (1999) Mortality due to asbestos-related causes among railway carriage construction and repair workers. Occup Med (Lond) 49: 536-539

Berry G (1994) Mortality and cancer incidence of workers exposed to chrysotile asbestos in the friction-products industry. Ann Occup Hyg 38: $539-546,413$

Berry G, Newhouse ML, Wagner JC (2000) Mortality from all cancers of asbestos factory workers in east London 1933 - 1980. Occup Environ Med 57: $782-785$

Bianchi C, Bianchi T (2007) Malignant mesothelioma: global incidence and relationship with asbestos. Ind Health 45: 379-387

Boffetta P (2007) Epidemiology of peritoneal mesothelioma: a review. Ann Oncol 18: 985 - 990

Clemmesen J, Hjalgrim-Jensen S (1981) Cancer incidence among 5686 asbestos-cement workers followed from 1943 through 1976. Ecotoxicol Environ Saf 5: 15-23

Darnton AJ, McElvenny DM, Hodgson JT (2006) Estimating the number of asbestos-related lung cancer deaths in Great Britain from 1980 to 2000. Ann Occup Hyg 50: 29-38

Delendi M, Riboli E, Peruzzo P, Stanta G, Cocchi A, Gardiman D, Sasco AJ, Giarelli L (1991) Comparison of diagnoses of cancers of the respiratory system on death certificates and at autopsy. IARC Sci Publ 112: 55-62

Driscoll T, Nelson DI, Steenland K, Leigh J, Concha-Barrientos M, Fingerhut M, Pruss-Ustun A (2005) The global burden of disease due to occupational carcinogens. Am J Ind Med 48: 419-431

Enterline PE, Hartley J, Henderson V (1987) Asbestos and cancer: a cohort followed up to death. Br J Ind Med 44: 396-401

Finkelstein MM (1984) Mortality among employees of an Ontario asbestoscement factory. Am Rev Respir Dis 129: 754-761

Finkelstein MM, Verma DK (2004) A cohort study of mortality among Ontario pipe trades workers. Occup Environ Med 61: 736-742

Gardner MJ, Winter PD, Pannett B, Powell CA (1986) Follow up study of workers manufacturing chrysotile asbestos cement products. $\mathrm{Br} J$ Ind Med 43: 726-732

Gasparrini A, Pizzo AM, Gorini G, Seniori CA, Silvestri S, Ciapini C, Innocenti A, Berry G (2008) Prediction of mesothelioma and lung cancer in a cohort of asbestos exposed workers. Eur J Epidemiol 23: $541-546$

Giaroli C, Belli S, Bruno C, Candela S, Grignoli M, Minisci S, Poletti R, Ricco G, Vecchi G, Venturi G (1994) Mortality study of asbestos cement workers. Int Arch Occup Environ Health 66: 7-11

Harding AH (2010) The Great Britain Asbestos Survey 1971-2005. Mortality of workers listed on the Great Britain Asbestosis of Mesothelioma Registers. Health and Safety Executive. http://www.hse. gov.uk/research/rrpdf/rr805.pdf

\section{ACKNOWLEDGEMENTS}

This work was made possible through the International Agency for Research on Cancer's Senior Visiting Scientist Award to Professor Julian Peto.

\section{Conflict of interest}

The authors declare no conflict of interest.

Supplementary Information accompanies the paper on British Journal of Cancer website (http://www.nature.com/bjc)

Hein MJ, Stayner LT, Lehman E, Dement JM (2007) Follow-up study of chrysotile textile workers: cohort mortality and exposure-response. Occup Environ Med 64: 616-625

Hodgson JT, Darnton A (2000) The quantitative risks of mesothelioma and lung cancer in relation to asbestos exposure. Ann Occup Hyg 44: 565-601

Hughes JM, Weill H, Hammad YY (1987) Mortality of workers employed in two asbestos cement manufacturing plants. Br J Ind Med 44: $161-174$

IARC (1987) Overall evaluations of carcinogenicity: an updating of IARC Monographs. IARC Monogr Eval Carcinogen Risks Hum 1-42(Suppl 7): $1-440$

Jones JS, Smith PG, Pooley FD, Berry G, Sawle GW, Madeley RJ, Wignall BK, Aggarwal A (1980) The consequences of exposure to asbestos dust in a wartime gas-mask factory. IARC Sci Publ 30: 637-653

Kolonel LN, Yoshizawa CN, Hirohata T, Myers BC (1985) Cancer occurrence in shipyard workers exposed to asbestos in Hawaii. Cancer Res 45: $3924-3928$

Krstev S, Stewart P, Rusiecki J, Blair A (2007) Mortality among shipyard coast guard workers: a retrospective cohort study. Occup Environ Med 64: $651-658$

Lacquet LM, van der LL, Lepoutre J (1980) Roentgenographic lung changes, asbestosis and mortality in a Belgian asbestos-cement factory. IARC Sci Publ 30: $783-793$

Levin JL, McLarty JW, Hurst GA, Smith AN, Frank AL (1998) Tyler asbestos workers: mortality experience in a cohort exposed to amosite. Occup Environ Med 55: $155-160$

Liddell FD, McDonald AD, McDonald JC (1997) The 1891-1920 birth cohort of Quebec chrysotile miners and millers: development from 1904 and mortality to 1992. Ann Occup Hyg 41: 13-36

Loomis D, Dement JM, Wolf SH, Richardson DB (2009) Lung cancer mortality and fiber exposures among north carolina asbestos textile workers. Occup Environ Med 66: 535-542

Marinaccio A, Scarselli A, Binazzi A, Mastrantonio M, Ferrante P, Iavicoli S (2008) Magnitude of asbestos-related lung cancer mortality in Italy. Br J Cancer 99: 173 - 175

McDonald AD, Case BW, Churg A, Dufresne A, Gibbs GW, Sebastien P, McDonald JC (1997) Mesothelioma in Quebec chrysotile miners and millers: epidemiology and aetiology. Ann Occup Hyg 41: 707-719

McDonald AD, Fry JS, Woolley AJ, McDonald JC (1983) Dust exposure and mortality in an American factory using chrysotile, amosite, and crocidolite in mainly textile manufacture. $\mathrm{Br}$ I Ind Med 40: 368-374

McDonald AD, Fry JS, Woolley AJ, McDonald JC (1984) Dust exposure and mortality in an American chrysotile asbestos friction products plant. $\mathrm{BrJ}$ Ind Med 41: $151-157$

McDonald AD, McDonald JC (1978) Mesothelioma after crocidolite exposure during gas mask manufacture. Environ Res 17: 340-346

Menegozzo M, Belli S, Bruno C, Canfora V, Costigliola A, Di CP, Di LL, Grignoli M, Palumbo F, Sapio P (1993) Mortality due to causes correlatable to asbestos in a cohort of workers in railway car construction. Med Lav 84: 193-200

Meurman LO, Pukkala E, Hakama M (1994) Incidence of cancer among anthophyllite asbestos miners in Finland. Occup Environ Med 51: $421-425$

Morabia A, Markowitz S, Garibaldi K, Wynder EL (1992) Lung cancer and occupation: results of a multicentre case-control study. $\mathrm{Br}$ J Ind Med 49: $721-727$ 
Musk AW, de Klerk NH, Reid A, Ambrosini GL, Fritschi L, Olsen NJ, Merler E, Hobbs MS, Berry G (2008) Mortality of former crocidolite (blue asbestos) miners and millers at Wittenoom. Occup Environ Med 65: $541-543$

Neuberger M, Kundi M (1990) Individual asbestos exposure: smoking and mortality - a cohort study in the asbestos cement industry. Br J Ind Med 47: $615-620$

Nicholson WJ, Perkel G, Selikoff IJ (1982) Occupational exposure to asbestos: population at risk and projected mortality - 1980-2030. Am J Ind Med 3: 259-311

Nurminen M, Karjalainen A (2001) Epidemiologic estimate of the proportion of fatalities related to occupational factors in Finland. Scand $J$ Work Environ Health 27: 161-213

Ohlson CG, Hogstedt C (1985) Lung cancer among asbestos cement workers. A Swedish cohort study and a review. Br J Ind Med 42: $397-402$

Ohlson CG, Klaesson B, Hogstedt C (1984) Mortality among asbestosexposed workers in a railroad workshop. Scand J Work Environ Health 10: $283-291$

Peto J, Decarli A, La VC, Levi F, Negri E (1999) The European mesothelioma epidemic. Br J Cancer 79: 666-672

Peto J, Doll R, Hermon C, Binns W, Clayton R, Goffe T (1985) Relationship of mortality to measures of environmental asbestos pollution in an asbestos textile factory. Ann Occup Hyg 29: 305-355

Piolatto G, Negri E, La VC, Pira E, Decarli A, Peto J (1990) An update of cancer mortality among chrysotile asbestos miners in Balangero, northern Italy. $\mathrm{Br}$ J Ind Med 47: 810-814

Pira E, Pelucchi C, Piolatto PG, Negri E, Discalzi G, La VC (2007) First and subsequent asbestos exposures in relation to mesothelioma and lung cancer mortality. Br J Cancer 97: 1300 - 1304

Puntoni R, Merlo F, Borsa L, Reggiardo G, Garrone E, Ceppi M (2001) A historical cohort mortality study among shipyard workers in Genoa, Italy. Am J Ind Med 40: 363-370

Raffn E, Villadsen E, Engholm G, Lynge E (1996) Lung cancer in asbestos cement workers in Denmark. Occup Environ Med 53: 399-402

Rake C, Gilham C, Hatch J, Darnton A, Hodgson J, Peto J (2009) Occupational, domestic and environmental mesothelioma risks in the British population: a case-control study. Br J Cancer 100: 1175-1183

Rossiter CE, Coles RM (1980) HM Dockyard, Devonport: 1947 mortality study. IARC Sci Publ 30: 713-721

Sanden A, Jarvholm B (1987) Cancer morbidity in Swedish shipyard workers 1978-1983. Int Arch Occup Environ Health 59: 455-462

Seidman H, Selikoff IJ, Gelb SK (1986) Mortality experience of amosite asbestos factory workers: dose-response relationships 5-40 years after onset of short-term work exposure. Am J Ind Med 10: $479-514$

Selikoff IJ, Seidman H (1991) Asbestos-associated deaths among insulation workers in the United States and Canada, 1967-1987. Ann NY Acad Sci 643: $1-14$
Sichletidis L, Chloros D, Spyratos D, Haidich AB, Fourkiotou I, Kakoura M, Patakas D (2009) Mortality from occupational exposure to relatively pure chrysotile: a 39-year study. Respiration 78: 63-68

Sluis-Cremer GK, Liddell FD, Logan WP, Bezuidenhout BN (1992) The mortality of amphibole miners in South Africa, 1946-1980. Br J Ind Med 49: $566-575$

Smailyte G, Kurtinaitis J, Andersen A (2004) Mortality and cancer incidence among Lithuanian cement producing workers. Occup Environ Med 61: $529-534$

Sullivan PA (2007) Vermiculite, respiratory disease, and asbestos exposure in Libby, Montana: update of a cohort mortality study. Environ Health Perspect 115: 579-585

Thomas HF, Benjamin IT, Elwood PC, Sweetnam PM (1982) Further followup study of workers from an asbestos cement factory. $\mathrm{Br} J$ Ind Med 39: $273-276$

Tola S, Kalliomaki PL, Pukkala E, Asp S, Korkala ML (1988) Incidence of cancer among welders, platers, machinists, and pipe fitters in shipyards and machine shops. Br J Ind Med 45: 209-218

Tomioka K, Natori Y, Kumagai S, Kurumatani N (2011) An updated historical cohort mortality study of workers exposed to asbestos in a refitting shipyard, 1947-2007. Int Arch Occup Environ Health 84: 959-967

Tulchinsky TH, Ginsberg GM, Iscovich J, Shihab S, Fischbein A, Richter ED (1999) Cancer in ex-asbestos cement workers in Israel, $1953-1992 . ~ A m ~ J$ Ind Med 35: 1-8

Ulvestad B, Kjaerheim K, Martinsen JI, Damberg G, Wannag A, Mowe G, Andersen A (2002) Cancer incidence among workers in the asbestoscement producing industry in Norway. Scand J Work Environ Health 28: $411-417$

Virta RL (2006) Worldwide asbestos supply and consumption trends from 1900 through 2003, 1 February 2006

Wang X, Lin S, Yano E, Qiu H, Yu IT, Tse L, Lan Y, Wang M (2011) Mortality in a Chinese chrysotile miner cohort. Int Arch Occup Environ Health; e-pub ahead of print 28 July 2011, doi:10.1007/s00420-011-0685-9

Wang XR, Yu IT, Qiu H, Wang MZ, Lan YJ, Tse LY, Yano E, Christiani DC (2012) Cancer mortality among Chinese chrysotile asbestos textile workers. Lung Cancer 75: 151-155

WHOSIS Mortality Database ICD-10 (2009) World Health Organization, Global Health Observatory. WHOSIS Mortality Database ICD-10, 21 April 2009. http://www.who.int/whosis/mort/download/en/index.html

Woitowitz HJ, Lange HJ, Beierl L, Rathgeb M, Schmidt K, Ulm K, Giesen T, Woitowitz RH, Pache L, Rodelsperger K (1986) Mortality rates in the Federal Republic of Germany following previous occupational exposure to asbestos dust. Int Arch Occup Environ Health 57: 161-171

World Health Organization (2008) WHO report on the global tobacco epidemic, 2008: the MPOWER package. Pop Dev Rev 34: 581

Yano E, Wang ZM, Wang XR, Wang MZ, Lan YJ (2001) Cancer mortality among workers exposed to amphibole-free chrysotile asbestos. $\mathrm{Am} J$ Epidemiol 154: $538-543$

This work is published under the standard license to publish agreement. After 12 months the work will become freely available and the license terms will switch to a Creative Commons Attribution-NonCommercial-Share Alike 3.0 Unported License. 